\title{
A Prospective Randomized Case-Control Study to Evaluate Mini Right Thoracotomy versus Conventional Sternotomy for Mitral Valve Repair in Rheumatic Heart Disease
}

\author{
Ashok Kumar Chahal1, Preeti Gehlaut', Sanjay Johar², Ashish Asija3 ${ }^{3}$, Divya Arora1, Naveen Malhotra², \\ Kuldeep Singh Lallar ${ }^{4}$, Shamsher Singh Lohchab1
}

\begin{abstract}
${ }^{1}$ Department of Cardiac Surgery, Pandit Bhagwat Dayal Sharma Post Graduate Institute of Medical Sciences, Rohtak, India
${ }^{2}$ Department of Anaesthesiology, Pandit Bhagwat Dayal Sharma Post Graduate Institute of Medical Sciences, Rohtak, India

${ }^{3}$ Department of Cardiac Surgery, Max Hospital, Delhi, India

${ }^{4}$ Department of Cardiology, Pandit Bhagwat Dayal Sharma Post Graduate Institute of Medical Sciences, Rohtak, India

Email: ashokchahal612@hotmail.com,preeti.gehlaut@gmail.com, sanjays321@yahoo.co.in, asijaashishasija@gmail.com, divyamlbjhs.arora@gmail.com, naveen_m2000@yahoo.com, susheela_taxak@hotmail.com, sslohchab@hotmail.com
\end{abstract}

How to cite this paper: Chahal, A.K., et al. (2016) A Prospective Randomized Case-Control Study to Evaluate Mini Right Thoracotomy versus Conventional Sternotomy for Mitral Valve Repair in Rheumatic Heart Disease. World Journal of Cardiovascular Surgery, 6 , 139-152.

http://dx.doi.org/10.4236/wjcs.2016.611021

Received: October 1, 2016

Accepted: November 1, 2016

Published: November 4, 2016

Copyright $\odot 2016$ by authors and Scientific Research Publishing Inc. This work is licensed under the Creative Commons Attribution International License (CC BY 4.0).

http://creativecommons.org/licenses/by/4.0/ (c) (i) Open Access

\begin{abstract}
Purpose: Right mini thoracotomy has been evaluated in many studies for mitral valve repair mainly in degenerative valvular disease but not in rheumatic heart disease. Mitral valve repair is more challenging in rheumatic etiology due to complexity of lesions. This prospective randomized case control study was designed to evaluate repair through mini right thoracotomy and to compare the clinical and echocardiographic outcomes with sternotomy in rheumatic patients. Methods: 25 patients of rheumatic heart disease underwent mitral valve repair through mini right thoracotomy (group I). Various clinical and functional parameters were compared with 25 patients of mitral valve repair through sternotomy (group II). On follow up the results were compared in both groups for clinical and echocardiographic parameters. Results: The various pre-operative demographic parameters were comparable in two groups. Equal rate of mitral valve repair (group I-21/25, 84\% and group II-21/25, $84 \%)$ was achieved in both groups. The various intra-operative and post-operative clinical parameters were better in group I .There were equivalent functional and valve related outcomes in both groups in term of NYHA class (1.28 \pm 0.613 vs $1.08 \pm$ $0.276, \mathrm{P}=0.144)$, post-operative mitral valve area $(2.43 \pm 0.891$ vs $2.82 \pm 0.662, \mathrm{P}=$ 0.090 ), incidence of more than mild mitral regurgitation (0) and mean pressure gradient across mitral valve $(4.98 \pm 3.33$ vs $4.23 \pm 1.5, \mathrm{P}=0.309)$. Conclusion: Mitral valve repair through mini right thoracotomy approach in rheumatic etiology is feasible and safe with equivalent rate of successful repair as compared to median ster-
\end{abstract}


notomy. It is associated with lesser morbidity, cosmetic advantage and lesser resource utilization.

\section{Keywords}

Rheumatic Heart Disease, Mitral Valve Repair, Minimally Invasive Mitral Valve Repair, Right Anterolateral Thoracotomy

\section{Introduction}

There are various approaches and techniques for minimally invasive cardiac operations depending on the type of surgery, availability of equipments and technical expertise of the team. Minimally invasive mitral valve surgery can be performed either by direct vision approach or endoscopic and robotic technique [1].

There is ample literature on the safety, feasibility, better cosmetic and equivalent surgical outcome of minimally invasive mitral valve repair over conventional mitral valve repair mainly in degenerative mitral valve disease [2] [3] [4]. Mitral valve repair is challenging one in rheumatic heart disease due to complexity of lesions. The literature is sparse on the use of minimally invasive approach for mitral valve repair in rheumatic heart disease. This randomized prospective case-control study was designed to evaluate the feasibility, safety and rate of mitral valve repair through limited right anterolateral thoracotomy approach and to compare the various perioperative outcome with conventional mid sternotomy approach in the rheumatic heart disease patients.

\section{Methods}

Fifty consecutive patients with rheumatic mitral valve disease were selected by prospective simple randomization over a period of 1.5 years to undergo either minimally invasive mitral valve repair (MIMVR group $1, \mathrm{n}=25$ ) or conventional mitral valve repair through median sternotomy (STMVR group II, $\mathrm{n}=25$ ). The procedure was performed through limited right anterolateral thoracotomy with peripheral femoral arterial cannulation in group I. The patients in group II were operated through median sternotomy and central cannulation for $\mathrm{CPB}$. The exclusion criteria for the study were: 1) previous cardiac surgery, 2) significant coronary artery disease, 3) associated aortic valve disease needing intervention and calcified ascending aorta, 4) external iliac or femoral artery stenosis. This study was approved by ethics committee of our institute and prior written informed consent was taken from the patients. The study was completed after 1.5 year as this was a thesis project and time limited. The patients were followed up for clinical and echocardiographic parameters.

\section{Surgical Techniques}

The general anesthesia was provided according to the standard protocol by endotracheal intubation with both lung ventilations. Trans-esophageal echocardiography 
(TEE) was done in both groups to assess mitral valve morphology and adequacy of repair. In the group 1 (MIMVR) patients were positioned supine with 30 degree elevation of right shoulder using a sand bag and right arm was slightly deviated from body. A 5 $6 \mathrm{~cm}$ skin incision was given in right sub mammary crease and right thoracic cavity was entered through $4^{\text {th }}$ intercostal space (Figure $1(\mathrm{~A})$ ). The pericardium was opened about $2 \mathrm{~cm}$ anterior to right phrenic nerve. Pericardial stay sutures were taken and right lung was retracted with a wet sponge under stay sutures. Normothermic cardiopulmonary bypass (CPB) was established with peripheral common femoral arterial cannulation by open Seldinger's technique (Fem flex II ${ }^{\mathrm{TM}}$ Femoral arterial cannula, Edward life sciences, Irvine USA) (Figure 1(B)) and superior vena cava (SVC), inferior vena cava (IVC) cannulation with metal tip right angled cannulas (Medtronic DLP, Minneapolis, MN, USA) (Figure $1(\mathrm{C})$ ). Aortic cross clamp was applied directly through thoracotomy

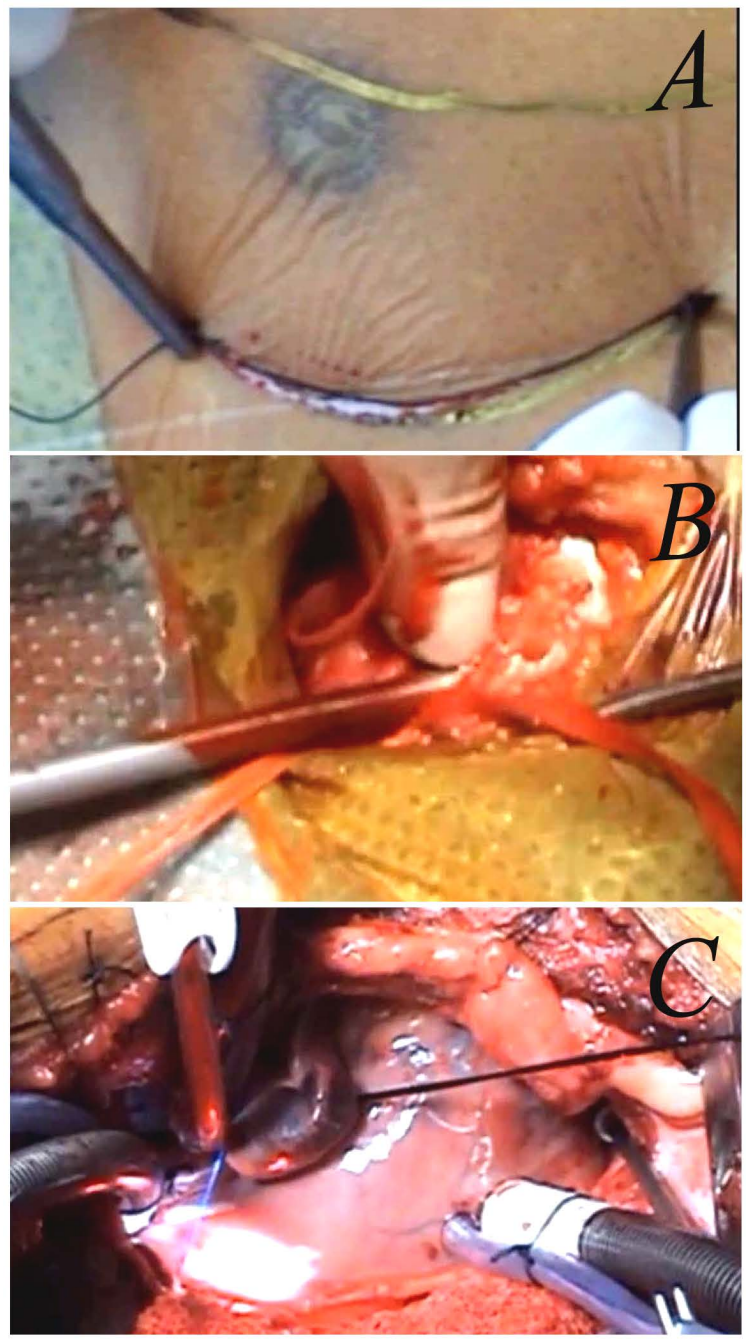

Figure 1. (A) Skin incision in sub-mammary crease. (B) Common femoral artery cannulation by open Seldinger's Technique. (C) Venous cannulation and cardioplegia needle insertion through thoracotomy incision. 
incision with long curved clamp (KLS Martin De Bakey-24-418-28-07, Germany). Myocardial protection was achieved by antegrade hyperkalemic cold blood cardioplegia solution through aortic root every 20 minutes (Figure $1(\mathrm{C})$ ). The left atrium was opened by developing Sondergaard's plane near the interatrial groove. Mitral valve was analyzed and suitability of repair was determined by degree of leaflets rigidity and subvalvular fusion (the criteria recommended by A Carpentier) [5]. Mitral valve repair was done by various repair techniques and ring annuloplasty. The steps of operative procedure are depicted in (Figures 2(A)-(F)). Left atrial appendage (LAA) was closed through
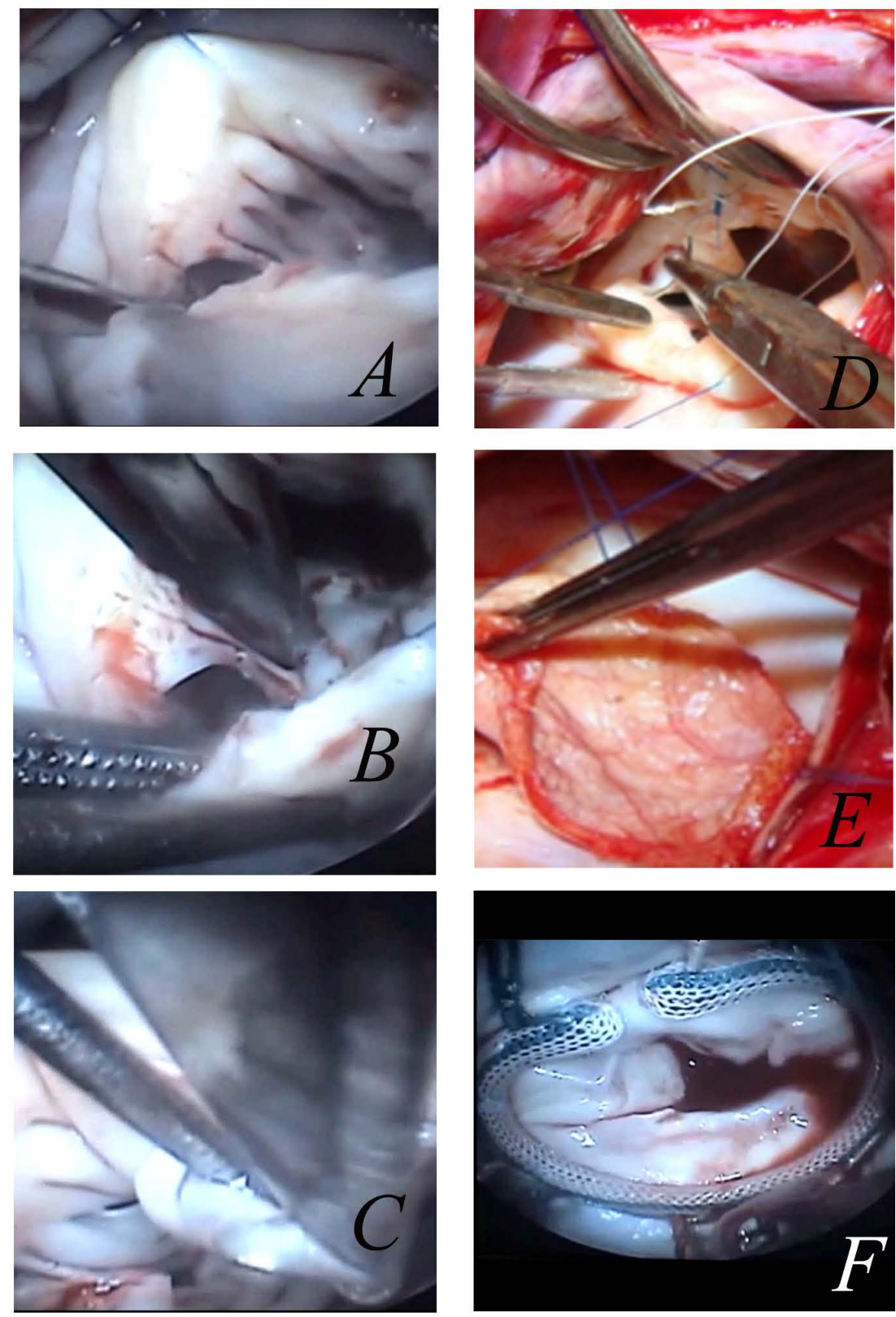

Figure 2. Different technique of mitral valve repair. (A) Commisurotomy, (B) papillotomy, (C) cutting of secondary level chordate, (D) artificial chordae implantation, (E) augmentation of posterior mitral leaflet with pericardial patch, $(\mathrm{F})$ ring annuloplasty. 
left atrium (LA) in two layers with 5 - 0 prolene. Left atriotomy was closed with 4 - 0 polypropylene suture. Right atriotomy was done where tricuspid valve repair was indicated. Cryocoxmaze III was done in patients having atrial fibrillation (AF). Pacing wire was fixed before removing cross clamp on still heart. Deairing and weaning off from $\mathrm{CPB}$ was done in standard fashion.

For the group II, a median sternotomy was done. CPB was established by aorto-bicaval cannulation after systemic heparinization. The other operative steps were same as in group 1. Left atrial appendage was closed through LA or externally in two layers with 5 - 0 prolene. The clinical and echocardiographic assessment was done on follow-up.

The results were analyzed as mean \pm standard deviation. The continuous variables were compared using student's t-test. The categorical variables were reported as percentage and compared using chi square test. For all statistical analysis a p value of 0.05 or less was considered significant.

\section{Results}

The demographics and pre-operative clinical characteristics are comparable. All the patients were having rheumatic valvular heart disease (Table 1).

Equal rate of mitral valve repair was achieved in both groups. The incidence of mitral valve replacement was $16 \%$ in both groups. All the replacement was done when repair was not possible due to advanced disease and non favourable morphology of mitral valve except in 1 patient of test group. This was an obese female patient with BMI of 29. In this patient exposure was very difficult and incision was extended. Due to poor exposure mitral valve replacement was done in this patient. There was conversion to sternotomy in one patient due to severe pleural adhesions. Overall use of blood product was lesser in test group.

Table 1. Demographics and pre-operative clinical characteristics in group I and group II.

\begin{tabular}{cccc}
\hline Variable & MIMVR (Group I) & STMVR (Group II) & P-value \\
\hline AGE (years) & $28.72 \pm 11.07$ & $31.12 \pm 11.68$ & 0.460 \\
Gender (male: female) & $6: 19$ & $7: 18$ & NS \\
Body Mass Index $\left(\mathrm{Kg} / \mathrm{m}^{2}\right)$ & $18.47 \pm 3.00$ & $18.34 \pm 2.98$ & 0.87. \\
New York Heart Association Class & $3.04 \pm 0.61$ & $3.12 \pm 0.60$ & 0.889 \\
Mitral Stenosis & $10(40 \%)$ & $7(28 \%)$ & 0.370 \\
Mitral Insufficiency & $7(28 \%)$ & $10(40 \%)$ & 0.370 \\
Mixed Lesion & $8(32 \%)$ & $8(32 \%)$ & - \\
Pulmonary Artery Pressure (mm of Hg) & $55.76 \pm 14.81$ & $65.32 \pm 20.07$ & 0.061 \\
Left Ventricular Ejection Fraction (\%) & $57.24 \pm 5.35$ & $56.32 \pm 3.90$ & 0.491 \\
Left Atrial size (mm) & $54.20 \pm 15.12$ & $55.84 \pm 13.30$ & 0.407 \\
Atrial Fibrillation & $10(40 \%)$ & $9(36 \%)$ & 0.770 \\
Tricuspid Regurgitation & $7(28 \%)$ & $8(32 \%)$ & 0.757 \\
\hline
\end{tabular}


Left atrial appendage closure was done in all patients in both groups. In thoracotomy group it can be done only through left atrium. But in sternotomy group, it can be done both through left atrium and externally (Table 2).

All the techniques of mitral valve repair can be used easily through minimally invasive approach. The annular sutures were taken initially. It helped in better exposure of mitral valve. In few patients, we faced difficulty in taking annular sutures at anterior mitral annulus and cutting of $2^{\circ}$ chordee at AML. These sutures were taken with long needle holder (Table 3).

Table 2. Intraoperative variables.

\begin{tabular}{cccc}
\hline Variable & MIMVR (N 25) & STMVR (N 25) & P value \\
\hline Mitral valve repair & $21(84 \%)$ & $21(84 \%)$ & 1 \\
Mitral valve replacement & $4(16 \%)$ & $4(16 \%)$ & 1 \\
Tricuspid Valve Repair & $7(28 \%)$ & $8(32 \%)$ & 0.757 \\
Atrial Fibrillation Surgery & 10 & 9 & 0.770 \\
Left atrial appendage closure & 25 & 25 & - \\
Aortic cross clamp time (Minute) & $154.92 \pm 45.53$ & $158.48 \pm 74.56$ & 0.839 \\
Cardio pulmonary bypass time (Minute) & $171.48 \pm 47.19$ & $184.08 \pm 83.83$ & 0.516 \\
Packed cell (PCV) & $3.64 \pm 1.11$ & $4.48 \pm 1.44$ & 0.026 \\
Fresh frozen plasma (FFP) & $2.52 \pm 0.871$ & $3.68 \pm 1.54$ & 0.002 \\
Plateler rich plasma (PRP) & $2.04 \pm 1.36$ & $3.20 \pm 2.04$ & 0.022 \\
Conversion to sternotomy & 1 & - & - \\
\hline
\end{tabular}

Table 3. Techniques used in mitral valve repair.

\begin{tabular}{cccccc}
\hline Variable & \multicolumn{2}{c}{ MIMVR (N-21) } & STMVR (N-21) & P value \\
\hline Commisurotomy & 19 & $(90.47 \%)$ & 14 & $(66.66 \%)$ & 0.06 \\
Papillotomy & 14 & $(66.66 \%)$ & 10 & $(47.61 \%)$ & 0.212 \\
Fenestration of Chordae & 14 & $(66.66 \%)$ & 10 & $(47.61 \%)$ & 0.212 \\
Secondary Chordae Cutting & 19 & $(90.47 \%)$ & 19 & $(90.47 \%)$ & 1 \\
Chordal Transfer & 2 & $(9.52 \%)$ & 3 & $(14.28 \%)$ & 0.633. \\
Chordal Transposition & 2 & $(9.52 \%)$ & 3 & $(14.28 \%)$ & 0.633 \\
Neo Chordae implantation & 5 & $(23.80 \%)$ & 6 & $(28.57 \%)$ & 0.725 \\
Cusp Thinning/Peeling & 4 & $(19.04 \%)$ & 7 & $(33.33 \%)$ & 0.292. \\
Cleft Closure & 6 & $(28.57 \%)$ & 4 & 19.04 & 0.468 \\
Leaflet Augmentation & 4 & $(19.04 \%)$ & 5 & 23.80 & 0.706 \\
Magic Stich Commissural Closure & 4 & $(19.04 \%)$ & 6 & 28.57 & 0.725 \\
\hline
\end{tabular}


The details of type and size of annuloplasty ring used in mitral valve repair are described in Table 4. All type of rings can be implanted through minimally invasive approach.

The AF ablation surgery was done in both groups. In MIMVR group Cut and sew cox Maze III was not possible due to limited access. In Biatrial cryocoxmaze III the Left atrial lesions were developed for 2 minutes and right atrial lesions were developed for 1 minute. All lesions were created by applying the Cryo Maze Probe (ATS Medical) for 2 minutes directly to myocardial tissue with temperatures reaching $-140^{\circ} \mathrm{C}$ to $-160^{\circ} \mathrm{C}$ (Table 5).

The mean duration of ventilator support chest tube removal, ICU stay, hospital stay and volume of chest tube drainage was significantly less in test group. This resulted in lesser hospital resource utilization due to lesser ICU stay and early hospital discharge (Table 6).

Table 4. Prosthetic annuloplasty rings/bands implanted in mitral valve repair.

\begin{tabular}{ccc}
\hline Prosthetic Annuloplasty Rings/Bands Implanted (Size no.) & MIMVR (N-21) & STMVR (N-21) \\
\hline $\begin{array}{c}\text { Carpentier Edward classic Rigid Annuloplasty ring } \\
\text { (Edward Life Sciences Irvine USA) }\end{array}$ & 1 & 0 \\
$\# 26$ & 11 & 4 \\
$\# 28$ & 1 & 4 \\
$\# 30$ & 0 & 4 \\
$\# 32$ & & \\
PROFILE 3D Rigid Annuloplasty Ring & & 1 \\
(Medtronic, Minneapolis, MN USA) & 1 & 2 \\
$\# 28$ & 4 & 2 \\
$\# 30$ & 1 & 1 \\
$\# 32$ & 1 & 3
\end{tabular}

Table 5. The details of atrial fibrillation ablation surgery.

\begin{tabular}{cccc}
\hline AF Surgery & MIMVR (N-10) & STMVR (N-9) & P value \\
\hline Biatrial Cryocoxmaze III & $10(40 \%)$ & $4(16 \%)$ & 0.058 \\
Cut and Sew Cox Maze III & 0 & $5(20 \%)$ & 0.018 \\
\hline
\end{tabular}

Table 6. Post-operative outcome.

\begin{tabular}{cccc}
\hline Variable & MIMVR (N-25) & STMVR (N 25) & P value \\
\hline Ventilatory Support (Hrs) & $10.42 \pm 4.74$ & $18.92 \pm 14.25$ & 0.006 \\
Chest Tube Drainage (ml) & $371.20 \pm 191.18$ & $554.80 \pm 205.59$ & 0.002 \\
Chest Tube Removal (Hrs) & $54.84 \pm 17.61$ & $75.68 \pm 30.04$ & 0.004 \\
Intensive Care Unit Stay (Hrs) & $67.84 \pm 28.33$ & $115.76 \pm 84.42$ & 0.010 \\
Hospital Stay (Days) & $6.64 \pm 2.09$ & $9.12 \pm 4.54$ & 0.016 \\
\hline
\end{tabular}


The overall incidence of various post-operative complications was lesser in MIMVR group. The mean no. of blood product use within 30 days was significantly less in MIMVR group. The dissatisfaction of patients with scar was significantly higher in STMVR group due to large externally visible scar than in MIMVR group (Figure 3(A)).

The mean length of scar was significantly less in MIMVR group. The small scar remains hidden under clothes and breast tissue (Figure 3(B), Figure 3(C) and Table 7).

Table 8 describes the clinical and echocardiographic outcome at follow-up. There are
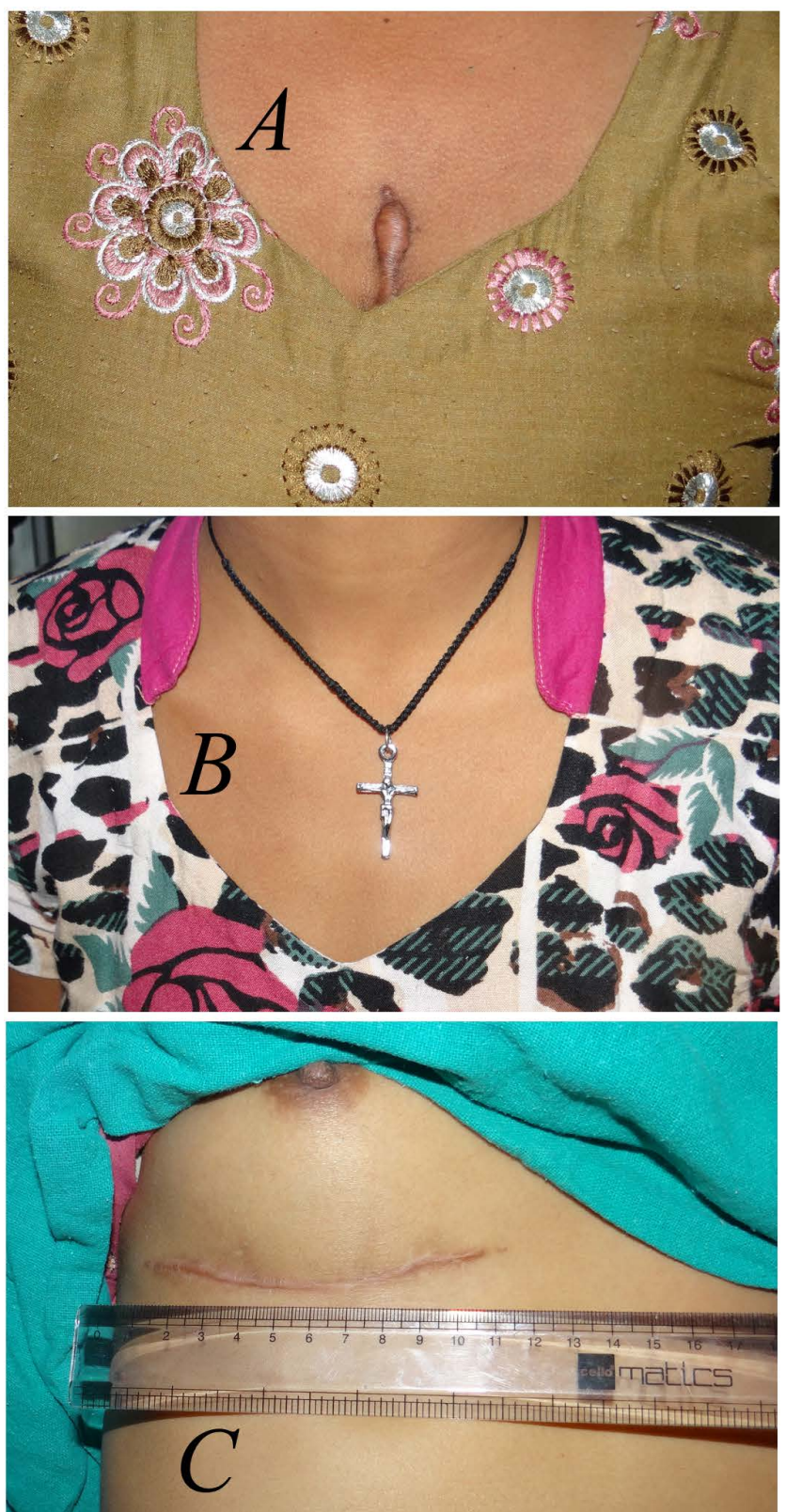

Figure 3. (A) Externally visible scar in sternotomy incision (cosmetic disadvantage). (B) Scar mark hidden under clothes in right mini thoracotomy incision. (C) Scar mark hidden under breast tissue (cosmetic advantage). 
Table 7. The details of various post-operative complications.

\begin{tabular}{|c|c|c|c|}
\hline Variable & MIMVR (N-25) & STMVR (N 25) & P value \\
\hline DEATH & $0(0 \%)$ & $0(0 \%)$ & - \\
\hline Respiratory Complication. & $1(4 \%)$ & $2(8 \%)$ & 0.356 \\
\hline Stroke & $0(0 \%)$ & $1(4 \%)$ & 0.312 \\
\hline Myocardial Infarction & $0(0 \%)$ & $0(0 \%)$ & - \\
\hline Bleeding. & $0(0 \%)$ & $4(16 \%)$ & 0.03 \\
\hline Re-Exploration for Bleeding & $0(0 \%)$ & $2(8 \%)$ & 0.03 \\
\hline Arrythmia & $1(4 \%)$ & $3(12 \%)$ & 0.297 \\
\hline Renal Failure. & $0(0 \%)$ & $0(0 \%)$ & - \\
\hline Gastrointestinal Events & $0(0 \%)$ & $2(8 \%)$ & 0.148 \\
\hline Pericardial Effusion & $0(0 \%)$ & $4(16 \%)$ & 0.037 \\
\hline Post-Pericardiotomy Syndrome & $0(0 \%)$ & $4(16 \%)$ & 0.037 \\
\hline Aortic Dissection/Injury & $0(0 \%)$ & $0(0 \%)$ & - \\
\hline Phrenic Nerve Palsy & $0(0 \%)$ & $0(0 \%)$ & - \\
\hline 30 Days Readmission & $1(4 \%)$ & $6(16 \%)$ & 0.04 \\
\hline Repeat Procedure & $0(8 \%)$ & $4(16 \%)$ & 0.037 \\
\hline \multicolumn{4}{|l|}{ Repeat Blood in $30 \mathrm{daYs}$} \\
\hline PCV & $0.52 \pm 0.714$ & $1.32 \pm 1.31$ & 0.010 \\
\hline FFP & $0.36 \pm 0.63$ & $1.52 \pm 1.68$ & 0.002 \\
\hline PRP & 0 & $1.36 \pm 1.91$ & $(<0.001)$ \\
\hline Superficial Wound Infection & $1(4 \%)$ & $6(24 \%)$ & 0.041 \\
\hline Groin Wound Infection & $2(8 \%)$ & $0(0 \%)$ & 0.148 \\
\hline Scar Length $(\mathrm{cm})$ & $9.32 \pm 1.97$ & $17.64 \pm 1.75$ & $(<0.05)$ \\
\hline Hypertrophic Scar & $2(4 \%)$ & $8(32 \%)$ & 0.033 \\
\hline Keloid & $0(0 \%)$ & $2(8 \%)$ & 0.148 \\
\hline Scar Dissatisfaction & $1(4 \%)$ & $10(40 \%)$ & 0.002 \\
\hline
\end{tabular}

Table 8. The clinical and echocardiographic outcomes at follow-up.

\begin{tabular}{|c|c|c|c|}
\hline Variable & MIMVR (N-25) & STMVR (N 25) & $P$ value \\
\hline NYHA Class & $1.28 \pm 0.613$ & $1.08 \pm 0.276$ & 0.144 \\
\hline Mitral Valve Area $\left(\mathrm{cm}^{2}\right)$ & $2.43 \pm 0.891$ & $2.82 \pm 0.662$ & 0.090 \\
\hline MILD Mitral Regurgitation & $4(16 \%)$ & $3(12 \%)$ & 0.683 \\
\hline >MILD Mitral Regurgitation & 0 & 0 & - \\
\hline Mean Pressure Gradient across Mitral Valve ( $\mathrm{mm}$ of $\mathrm{Hg}$ ) & $4.98 \pm 3.33$ & $4.23 \pm 1.5$ & 0.309 \\
\hline Infective Endocarditis & 0 & 0 & - \\
\hline Follow up (months) & $13.60 \pm 5.42$ & $12.12 \pm 6.67$ & 0.394 \\
\hline
\end{tabular}

equivalent and good operative and functional outcome in term of NYHA class $(1.28 \pm$ 0.613 vs $1.08 \pm 0.276)$, post-operative mitral valve area $(2.43 \pm 0.891$ vs $2.82 \pm 0.662)$, incidence of more than mild $\mathrm{MR}(0)$ and mean pressure gradient across mitral valve $(4.98 \pm 3.33$ vs $4.23 \pm 1.5)$ in two group .There was no incidence of infective endocarditis in both groups (Table 8 ). 


\section{Discussion}

The objective of minimally invasive mitral valve surgery (MIMVS) is to provide a safe and effective approach for mitral valve surgery with benefits provided by minimally invasive approach. Surgical approach vary from centre to centre, depends on availability of resources and technical expertise of the surgical team.

We did MIMVR through direct vision mini right thoracotomy with peripheral femoral arterial cannulation in rheumatic patients. There is a potential concern about retrograde femoral/aortic dissection and acute limb ischaemia with peripheral arterial cannulation but its incidence is very low [6]. It did not occur in anyone of our patients. Femoral artery was closed at the site of cannulation by tying the purse string suture. There was no incidence of patch repair in our patients as described by other studies [7]. Direct SVC, IVC cannulation can be easily done which eliminates the risk of late venous thrombosis, thromboembolism and thrombophlebitis. Cardioplegia needle and aortic cross clamp can be easily placed through the thoracotomy with the aid of traction suture taken on aorta. TEE helps in effective deairing of heart and assessment of mitral valve repair postoperatively [8].

The base line demographic parameter and preoperative patient characteristic in the two groups were comparable (Table 1). Successful Mitral valve repair was possible in $84 \%$ of patients in each group. The various techniques of mitral valve repair were used in both groups with ease and accuracy. Annuloplasty ring of different sizes and character were used depending upon the disease and patient characteristics in both the groups. Various studies reported more than $90 \%$ rate of mitral valve repair by minimally invasive approach in degenerative mitral valve disease [2] [9] [10]. Our rate is slightly less but it is in rheumatic etiology. More over it is equal in both groups which show that it does not depend on approach but on etiology of disease. The post operative NYHA functional class and various surgical outcomes like mitral valve area, pressure gradient across mitral valve and incidence of residual mild MR was not statistically different in two groups. There was not more than mild MR in both groups (Table 8). These outcomes shows that equivalent and high rate of mitral valve repair can be achieved in rheumatic heart disease patients through minimally invasive approach. All the techniques of mitral valve repair can be used successfully and all kind of prosthesis can be inserted. Many studies had shown the good results of mitral valve repair through mini right thoracotomy approach in degenerative disease [3] [9] [10].

Concomitant tricuspid valve surgery, internal closure of left atrial appendage and AF ablation surgery (cryocoxmaze III) can be done through minimally invasive approach. Pfannmuller et al. also reported the feasibility of tricuspid valve repair through MICS approach [11]. Saint et al. and wolf et.al reported surgical ablation of AF by MICS approach [12] [13]. The adequate exposure for these procedures was achieved. In MIMVR group all the patients were free from AF at 1 year. Cut and sew coxmaze III procedure seemed impossible hence was not done in mini right thoracotomy group. It was done in five patients of mid sternotomy group. Left atrial appendage closure (LAA) is preferred in patients of mitral valve repair to avoid the risk of thromboembolism [14]. In mini 
right thoracotomy approach it can be achieved by internal closure of LAA through left atrium. In mid sternotomy group it can be done both ways internally or externally.

In our study the mean aortic cross clamp time and CPB time was lesser in test group than control group. This is in contrast to other studies where this is opposite [6] [15] [16] [17]. This may be due to the reason that number of concomitant procedure were higher in control group and in five patients cut and sew coxmaze III procedure was done leading to higher cross clamp and total bypass time.

As with other studies the mean unit of blood products used, post operative ventilatory need, chest tube drainage, total ICU and hospital stay was significantly less in MIMVR group [7] [15] [16] [17].

The rate of bleeding and re-exploration for bleeding were higher in STMVR group. Majority of patients who had bleeding complications (4) and reexploration (2/4) were, who had cut and sew coxmaze III procedure. There was stroke in one patient of control group and it was the patient in whom surgical cut and sew maze was done. Other studied also reported higher bleeding complications in sternotomy group [10] [15] [16] [17]. But in our study these complication in control group seems to be procedure related (Cut and Sew coxmaze III) and not approach related (Table 7).

There was no incidence of aortic dissection/injury and phrenic nerve palsy (Table 7). This is in contrast to metaanalysis by Cheng et al. [17]. This difference may be due to small no. of patients in this study.

Post pericardiotomy syndrome, 30-days readmission rate, rate of repeat procedure, were higher in STMVR group. In two patients surgical drainage of pericardial fluid was needed. The rate of 30-days blood product usage was significantly higher in STMVR group (Table 7). There are many studies and metaanalysis which have clearly shown the higher incidence of these complications in sternotomy patient [6] [7] [17].

There was no difference in mortality, myocardial infarction rate, arrthymias, renal failure, gastro-intestinal events and rate of phrenic nerve palsy between MIMVR and STMVR group. These events are variably reported by many studies [16] [18].

Overall wound related complications, hypertrophic scar and keloid formation was higher in STMVR group. MIMVS provided a clear cosmetic advantage to patients as externally visible scar was not present. A small submammary scar remains hidden under clothes and breast (Figure 3(b) and Figure 3(c)). They were more comfortable in their daily routine and professional life. They can comfortably attend cultural events and other functions. Ganie et al. also proved the less scar visibility and better cosmesis with limited thoracotomy approach [19]. The mean length of incision was significantly less in MIMVR group $(9.32 \pm 1.97 \mathrm{~cm}$ vs $17.64 \pm 1.75 \mathrm{~cm})$. In a meta analysis Cheng et al. reported mean incision length of $6.5 \pm 1.3 \mathrm{~cm}$ in MIMVS group [17]. In most of these studies videoscopic assistance was taken with peripheral arterial and venous cannulation. Operations in our study were done under direct vision. Ganie et al. also reported mean incision length of $14.8 \pm 2.3 \mathrm{~cm}$ [19]. Filky et al.reported incision length between $12-15 \mathrm{~cm}$ in their study [20]. The incision length can be reduced with the use of videoscopic and robotic assistance. But endoscopic and robotic techniques are very 
costly, require a significant learning curve, special instrument and resource utilization and still are not widely used. Surgery under direct vision can be done with routine instruments. Although length of incision is important but for cosmetic advantage location of incision also plays a role.

\section{Conclusion}

Mitral valve repair through mini right thoracotomy approach in rheumatic etiology is feasible and safe with equivalent and high rate of successful repair as compared to median sternotomy patients. Right mini thoracotomy approach is associated with lesser morbidity and lesser resource utilization in comparison to conventional sternotomy. Concomitant tricuspid valve repair and cryocoxmaze III procedure is possible through mini right thoracotomy. There are better cosmetic results with right mini thoracotomy in comparison to conventional sternotomy.

\section{Limitations}

1) The number of patients in each group were small as the number of valve suitable for repair are very less due to complexity of lesions in rheumatic etiology and time limitation of this study.

2) There was initial learning curve with MIMVR.

3) MIMVR was done with use of routine instruments.

4) The cut and sew maze procedure were done in sternotomy group which may have overall impact on higher morbidity and complications in sternotomy group.

Disclosure: All authors declare that there is no conflict of interest in this article. The authors declare that the patient has given approval and consent to the publication of this article.

Ethical Approval: All procedures performed in studies involving human participants were in accordance with the ethical standards of the institutional and/or national research committee and with the 1964 Helsinki declaration and its later amendments or comparable ethical standards.

Source of Funding: There was no source of financial assistance for this study.

\section{References}

[1] Doty, D.B., DiRusso, G.B. and Doty, J.R. (1998) Full-Spectrum Cardiac Surgery through a Minimal Incision: Mini-Sternotomy (Lower Half) Technique. The Annals of Thoracic Surgery, 65, 573-577. http://dx.doi.org/10.1016/S0003-4975(97)01368-4

[2] Speziale, G., Nasso, G. and Esposito, G. (2011) Results of Mitral Valve Repair for Barlow Disease (Bileaflet Prolapse) via Right Minithoracotomy versus Conventional Median Sternotomy: A Randomized Trial. The Journal of Thoracic and Cardiovascular Surgery, 142, 77-83. http://dx.doi.org/10.1016/j.jtcvs.2010.08.033

[3] Goldstone, A.B., Atluri, P. and Szeto, W.Y. (2013) Minimally Invasive Approach Provides at Least Equivalent Results for Surgical Correction of Mitral Regurgitation: A PropensityMatched Comparison. The Journal of Thoracic and Cardiovascular Surgery, 145, 748-756. http://dx.doi.org/10.1016/j.jtcvs.2012.09.093 
[4] Cao, C., Gupta, S., Chandrakumar, D., Nienaber, T.A., Indraratna, P. and Ang, S.C. (2013) A Meta-Analysis of Minimally Invasive Versus Conventional Mitral Valve Repair for Patients with Degenerative Mitral Disease. Annals of Cardiothoracic Surgery, 2, 693-703.

[5] Carpentier, A., Adams, D.H. and Filsoufi, F. (2010) Pathophysiology, Preoperative Valve Analysis, and Surgical indications. Reconstructive Valve Surgery. 1st Edition, WB Saunders Elsevier, Maryland Heights Missouri, 49.

[6] Gammie, J.S., Zhao, Y., Peterson, E.D., O’Brien, S.M., Rankin, J.C. and Griffith, B.P. (2010) Less-Invasive Mitral Valve Operations: Trends and Outcomes from the Society of Thoracic Surgeons Adult Cardiac Surgery Database. The Annals of Thoracic Surgery, 90, 1401-1410. http://dx.doi.org/10.1016/j.athoracsur.2010.05.055

[7] Mihaljevic, T., Cohn, L.H., Unic, D., Aranki, S.F., Couper, G.S. and Byrne, J.G. (2004) One Thousand Minimally Invasive Valve Operations, Early and Late Results. Annals of Surgery, 240, 529-534. http://dx.doi.org/10.1097/01.sla.0000137141.55267.47

[8] Carpentier, A., Loulmet, D., Aupècle, B. and Kieffer, J.P, et al. (1998) Chirurgie à cœur ouvert assistée par ordinateur. Premier cas opéré avec succès First Computer Assisted Open Heart Operation. Comptes Rendus de P Académie des Sciences-Series III-Sciences de la Vie, 321, 437-442. http://dx.doi.org/10.1016/S0764-4469(98)80309-0

[9] Raanani, E., Spiegelstein, D. and Sternik, L. (2010) Quality of Mitral Valve Repair: Median Sternotomy versus Port-Access Approach. The Journal of Thoracic and Cardiovascular Surgery, 140, 86-90. http://dx.doi.org/10.1016/j.jtcvs.2009.09.035

[10] Iribarne, A., Russo, M.J., Easterwood, R., Hong, K.N., Yang, J. and Cheema, F.H. (2010) Minimally Invasive versus Sternotomy Approach for Mitral Valve Surgery: A Propensity Analysis. The Annals of Thoracic Surgery, 90, 1471-1478.

http://dx.doi.org/10.1016/j.athoracsur.2010.06.034

[11] Pfannmüller, B., Davierwala, P., Hirnle, G., Borger, M.A., Misfeld, M., Garbade, J., et al. (2013) Concomitant Tricuspid Valve Repair in Patients with Minimally Invasive Mitral Valve Surgery. Annals of Cardiothoracic Surgery, 2, 758-764.

[12] Saint, L.L., Lawrance, C.P.., Leidenfrost, J.E., Robertson, J.O. and Damiano Jr., R.J. (2014) How I Do It: Minimally Invasive Cox-Maze IV Procedure. Annals of Cardiothoracic Surgery, 3, 117-119.

[13] Wolf, R.K. and Burgess, S. (2014) Minimally Invasive Surgery for Atrial Fibrillation-Wolf Mini Maze Procedure. Annals of Cardiothoracic Surgery, 3, 122-123.

[14] Saady, N., Obel, O. and Camm, A. (1999) Left Atrial Appendage: Structure, Function, and Role in Thromboembolism. Heart, 82, 547-554. http://dx.doi.org/10.1136/hrt.82.5.547

[15] Holzhey, D.M., Shi, W. and Borger, M.A. (2011) Minimally Invasive versus Sternotomy Approach for Mitral Valve Surgery in Patients Greater than 70 Years Old: A PropensityMatched Comparison. The Annals of Thoracic Surgery, 91, 401-405.

http://dx.doi.org/10.1016/j.athoracsur.2010.08.006

[16] Seeburger, J., Borger, M.A., Doll, N., Walther, T., Passage, J. and Falk, V. (2009) Comparison of Outcomes of Minimally Invasive Mitral Valve Surgery for Posterior, Anterior and Bileaflet Prolapsed. European Journal of Cardio-Thoracic Surgery, 36, 532-538. http://dx.doi.org/10.1016/j.ejcts.2009.03.058

[17] Cheng, D.C.H., Martin, J., Lal, A., Diegeler, A., Folliguet, T.A. and Nifong, L.W. (2011) Minimally Invasive Versus Conventional Open Mitral Valve Surgery. A Meta-Analysis and Systematic Review. Innovations, 6, 84-103.

[18] Vollroth, M., Seeburger, J. and Garbade, J. (2012) Minimally Invasive Mitral Valve Surgery Is a Very Safe Procedure with Very Low Rates of Conversion to Full Sternotomy. European 
Journal Cardio-Thoracic Surgery, 42, 13-15. http://dx.doi.org/10.1093/ejcts/ezs195

[19] Ganie, F.A., Ahangar, A.G., Shah, Z.A., Lone, G.N., Lone, H., Wani, M.L., et al. (2013) Right Anterolateral Thoracotomy a Minimally Invasive Approach to Mitral Valve Replacement. Muller Journal of Medical Sciences and Research, 4, 53-56.

http://dx.doi.org/10.4103/0975-9727.118223

[20] Fiky, M.M., Sayegh, T.E., El-Beishry, A.S., Aziz, M.A., Enein, H.A., Waheid, S., et al. (2000) Limited Right Anterolateral Thoracotomy for Mitral Valve Surgery. European Journal of Cardio-Thoracic Surgery, 7, 10-13.

Submit or recommend next manuscript to SCIRP and we will provide best service for you:

Accepting pre-submission inquiries through Email, Facebook, LinkedIn, Twitter, etc. A wide selection of journals (inclusive of 9 subjects, more than 200 journals)

Providing 24-hour high-quality service

User-friendly online submission system

Fair and swift peer-review system

Efficient typesetting and proofreading procedure

Display of the result of downloads and visits, as well as the number of cited articles Maximum dissemination of your research work

Submit your manuscript at: http://papersubmission.scirp.org/

Or contact wjcs@scirp.org 